\title{
How Health Risk from Radiation is Assessed
}

\section{Linda Rahm-Crites}

July 1994

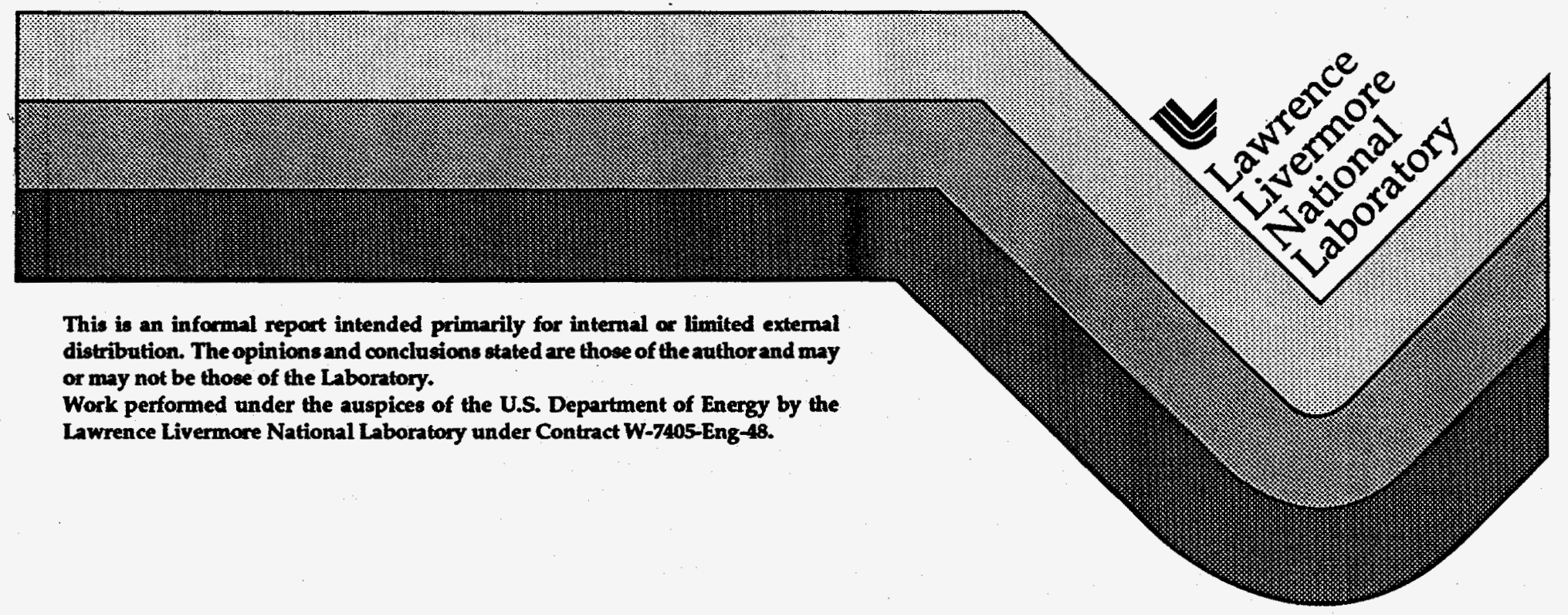

This is an informal report intended primarily for internal of limited external distribution. The opinions and conclusions stated are those of the author and may or may not be those of the Laboratory.

Work performed under the auspices of the U.S. Department of Energy by the Lawrence Livermore National Laboratory under Contract W-7405-Eng-48. 


\section{DISCLAIMER}

This document was prepared as an account of work sponsored by an agency of the United States Government. Neither the United States Government nor the University of California nor any of their employees, makes any warranty, express or implied, or assumes any legal liability or responsibility for the accuracy, completeness, or usefulness of any information, apparatus, product, or process disclosed, or represents that its use would not infringe privately owned rights. Reference herein to any specific commercial products, process, or service by trade name, trademark, manufacturer, or otherwise, does not necessarily constitute or imply its endorsement, recommendation, or favoring by the United States Government or the University of California. The views and opinions of authors expressed herein do not necessarily state or reflect those of the United States Government or the University of California, and shall not be used for advertising or product endorsement purposes.

This report has been reproduced directly from the best available copy.

Available to DOE and DOE contractors from the Ofice of Scientific and Technical Information

P.O. Box 62, Oak Ridge, TN 37831

Prices available from (615) 576-8401, FTS 626-8401

A vailable to the public from the

National Technical Information Service

US. Department of Commerce

5285 Port Royal Rd.

Springfield, VA 22161 


\section{DISCLAIMER}

Portions of this document may be illegible in electronic image products. Images are produced from the best available original document. 
Linda Rahm-Crites

Fission Energy and Systems Safety Program

20201 Century Boulevard

Germantown, Maryland 20874

(301) $916-6684$

\section{How Health Risk from Radiation Is Assessed}

This information is provided as a context for understanding discussions of radiation exposure and potential health effects in National Environmental Policy Act (NEPA) documents, such as Environmental Assessments (EAs) and Environmental Impact Statements (EISs).

\section{Radiation}

Radiation is the excess energy given off when one form of an element (an isotope) changes into some other form. In emitting radiation, an isotope can become a different element or a different isotope of the same element. This process occurs because unstable isotopes tend to decay until they reach a more stable state. As this happens, they give off atomic particles such as neutrons, alpha particles, and beta particles, or waves of pure energy such as gamma rays.

Some types of radiation (for example, radio waves) have no effect on living tissue. Other types have sufficient energy to alter the structure of the atoms which make up individual cells. When this type of radiation strikes an atom, it can dislodge an electron, causing the electrically neutral atom to become a charged particle, or ion. Hence, it is called ionizing radiation. The cell whose atoms are affected in this way may simply repair itself, or it may die, or it may reproduce more altered cells. If the alteration affects reproductive cells, it can cause heritable genetic damage.

Of the three main types of ionizing radiation, alpha particles are the least penetrating but potentially the most damaging. Alpha particles cannot penetrate the outer layer of skin; however; alpha-emitting isotopes in air or food, for example, can be inhaled or ingested into the body, where they continue to decay and deposit their radiation in organ tissues. Beta particles are faster and more penetrating than alphas, but, like alphas, cause most damage when they are inside the body as a result of inhalation or ingestion. Gamma rays are similar to x-rays but more energetic, and they can penetrate most materials except thick shields of concrete, lead, and steel.

\section{Sources of Radiation}

Everyone in the world is constantly exposed to background radiation, coming both from the external environment (e.g., cosmic rays and radioactive materials in the earth) and from within the human body itself (naturally-occurring potassium- 40 and other ingested or inhaled radioactive particles). The figure below provides a source breakdown of the radiation received over a year by a "typical" United States resident, based on numbers from the National Council on Radiation Protection and Measurements (NCRP 1987). 


\section{Typical Radiation Sources}

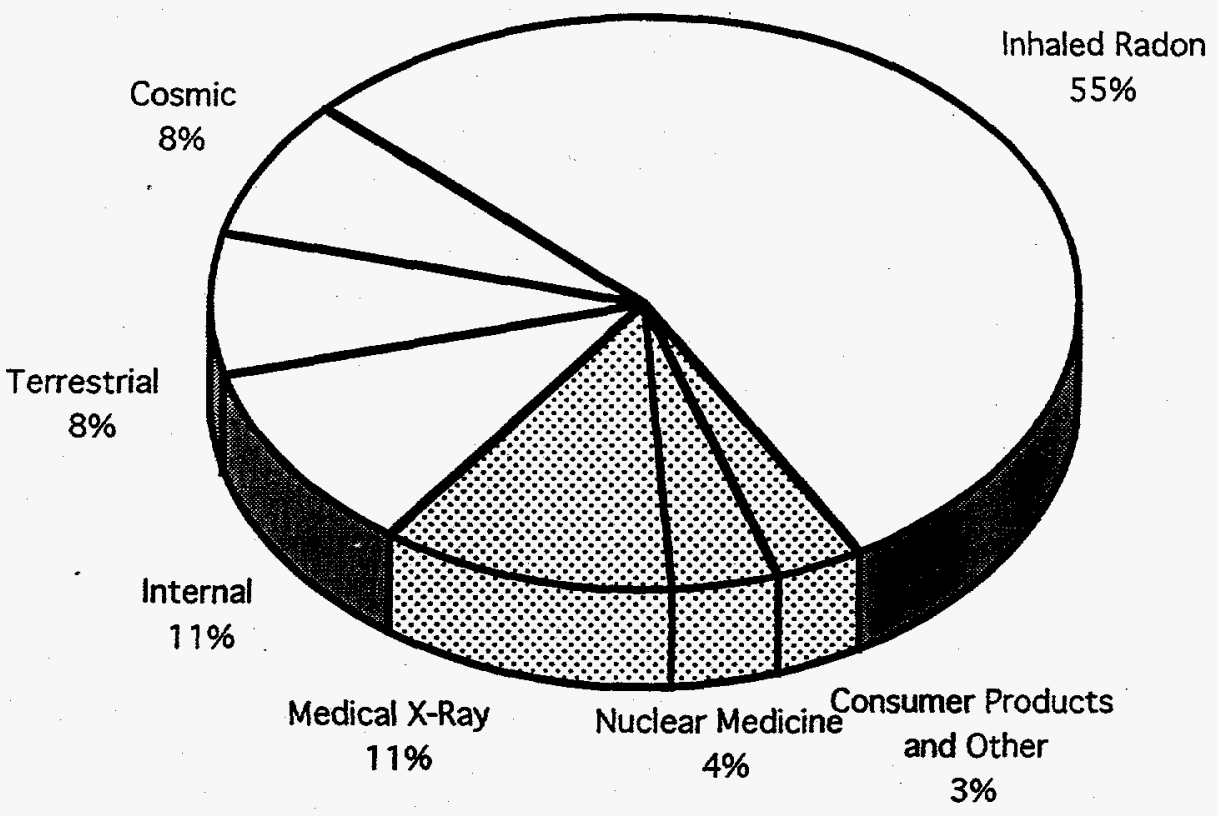

White areas denote natural radiation, and shaded areas denote man-made radiation.

As shown in the figure, by far the greater portion (roughly 82 percent) of our background radiation dose is attributable to natural sources, including radon, which comes from radium in the earth (because radon only affects the body after it is inhaled, it is regarded as an internal, rather than an external, source). The remaining 18 percent of the radiation we receive is man-made radiation resulting from medical procedures, nuclear testing, and consumer products such as color TVs. Individual doses, of course, will vary according to such factors as place of residence, occupation, and personal habits. A person who travels frequently by airplane or lives in a high altitude, for example, will receive a larger than average amount of radiation from cosmic rays.

\section{What is Meant by Dose}

It is possible to calculate the amount of energy which tissue absorbs from ionizing radiation (sometimes called the absorbed dose). However, absorbed dose does not provide a very good idea of what the biological effects of that radiation will be. Why not? Because different types of radiation cause different degrees of damage. For example, alpha radiation is about 20 times more damaging to human tissue than beta or gamma radiation.

When calculating health risk, therefore, it is more useful to talk about dose equivalent, which is obtained by multiplying the absorbed dose by a quality factor that varies to account for the different biological effects produced by different types of radiation. 
Dose equivalent is measured in rem or millirem (mrem). A millirem is $1 / 1000$ rem, or 0.001 rem.

\begin{tabular}{|r|r|}
\hline Dose Equivalent Measures \\
\hline \hline $1 \mathrm{mrem}$ & $=0.001 \mathrm{rem}($ or $1 / 1000 \mathrm{rem})$ \\
$10 \mathrm{mrem}$ & $=0.01 \mathrm{rem}($ or $1 / 100 \mathrm{rem})$ \\
$100 \mathrm{mrem}$ & $=0.1 \mathrm{rem}($ or $1 / 10 \mathrm{rem})$ \\
$1000 \mathrm{mrem}$ & $=1 \mathrm{rem}$ \\
\hline
\end{tabular}

To provide some points of reference, the average yearly individual dose equivalent from background radiation in the United States (see pie chart, above) is estimated to be around 365 mrem, or .365 rem. A routine chest $\mathrm{x}$-ray using modern equipment produces a dose of around 10 mrem (0.01 rem); a one-way airplane trip from New York to Los Angeles, about 2.5 mrem $(0.0025 \mathrm{rem}) .^{1}$

Various other expressions incorporating the term "dose equivalent" are used to specify particular types of biological effect and to provide the basis for more accurate calculations. Although readers will probably not need to distinguish among all of them, these expressions (or their acronyms) do appear frequently in discussions of radiological health risk. Here is a list of brief definitions.

Effective Dose Equivalent (EDE) totals the dose equivalents received by specified tissues or organs of the body, each of which has been multiplied by an appropriate weighting factor. The weighting factor is necessary because organs differ in their sensitivity to different types of radiation. EDE includes dose from both internal and external sources. AEDE indicates annual effective dose equivalent.

Committed Dose Equivalent (CDE) is the dose equivalent that will be received by a tissue or organ over a 50-year period after an intake of radioactive material. CDE is used, for example, to measure the effect of already-inhaled airborne radioactivity; it does not include radiation which is received from external sources.

Committed Effective Dose Equivalent (CEDE) is the sum of the committed dose equivalents to body organs or tissues, each multiplied by the appropriate weighting factor. Again, this is radiation received from internal (i.e. already inhaled or ingested) sources.

Total Effective Dose Equivalent (TEDE) is the sum of the EDE from external sources and the CEDE from internal sources.

Collective Effective Dose Equivalent is the total of the effective dose equivalents for all the individuals in a specified group or population--for example, the workers in a plant or the members of the public along a transportation route.

The different types of dose equivalent are all measured in rem or millirem, except for the collective effective dose equivalent, which is measured in person-rem. Person-rem is the number of individuals in the designated group multiplied by the average individual effective dose equivalent

\footnotetext{
${ }^{1}$ Dose equivalents for DOE activities are calculated independently of, and do not include, background radiation. DOE Order 5400.5 limits radiological exposure of members of the public from routine DOE activities to an effective dose equivalent of no more than $100 \mathrm{mrem}(0.1 \mathrm{rem})$ per year. which is consistent with NCRP's recommendation for public exposures from man-made sources excluding medical sources (NCRP Report No. 91).
} 
(in rem or millirem). For example, if each individual in a population of 1000 people received 5 mrem $(0.005 \mathrm{rem})$, the total population would receive a collective effective dose equivalent of 5 person-rem, as follows:

$$
1000 \text { people } \times 0.005 \text { rem }=5 \text { person-rem. }
$$

Conversely, the average individual dose equivalent can be derived from collective dose simply by dividing the collective effective dose equivalent by the number of people in the group:

$$
5 \text { person-rem } \div 1000 \text { people }=0.005 \text { rem (or } 5 \text { mrem) }
$$

\section{Converting Dose to Risk}

The likelihood that a dose of radiation will result in death from cancer at some future time (i.e. a latent cancer fatality, or LCF) can be estimated by multiplying the dose equivalent by a risk factor, or dose-to-risk conversion factor. Conversion factors, which are based on studies of atomic bomb survivors and others, provide approximate predictions of the health effects to be expected from a given radiological exposure.

Following recommendations of the Nuclear Regulatory Commission, the Department of Energy currently uses risk conversion factors of $4 \times 10^{-4}$ (0.0004 LCFs) per person-rem for workers and $5 \times 10^{-4}$ (0.0005 LCFs) per person-rem for the general public (NRC 1991; DOE 1993). The conversion factor for the general public is slightly higher than that for workers because the general public includes infants and children, who are more susceptible to cancer.

Note: Because the numbers used in health risk calculations are often very small, they are presented, for convenience, by means of negative exponents. The negative exponent after 10 (e.g. $\left.{ }^{-4}\right)$ tells how many spaces to the right of the decimal point to put the number that appears before the multiplication sign. $5 \times 10^{-4}$ tells us to place 5 in the fourth place to the right of the decimal point: $0.000 \underline{5}$. Hence,

$$
\begin{aligned}
& 5 \times 10^{-2}=0.05 \\
& 5 \times 10^{-3}=0.005 \\
& \text { and so on. }
\end{aligned}
$$

Multiplying the collective effective dose equivalent received by a group of people (in person-rem) by the appropriate risk conversion factor produces a number which can be used to estimate potential health risk. Thus, for a population of workers receiving a collective dose of 20 personrem, we multiply 20 by the conversion factor for workers (sometimes called the occupational risk factor):

$$
20 \text { person-rem } \times 0.0004 \text { [conversion factor }]=0.008 \text {. }
$$

The result, 0.008 , can also be expressed as a probability of eight chances out of 1000 (because it represents $8 / 1000$ or eight one thousandths). For convenience, we can reduce the fraction to $1 / 125$ or one chance in 125 . What does this mean? 
It is important to note that this number, which is significantly less than 1 , is a probability, not a proportion. It does not mean that one worker out of every 125 will die of cancer. It means that the chance that anyone in the group will develop a fatal cancer as a result of this dose is one in 125 .

If we were to compare this example with what happens when dice are rolled, it would be like this:

We have a large red 125-sided die, one side of which is white;

this die is thrown once for the entire group;

the chance (one in 125) that the white side will land on top is the same as the chance that there will be one cancer fatality in the group due to this exposure.

Health risk calculations in NEPA documents apply only to the actions described and do not include risk from other sources. A prediction of low or negligible risk to a specific population in an EA or an EIS does not imply, of course, that no one, or only one or two people, in that population will ever die of cancer. The current overall death rate from cancer in the United States is between 20 and 25 percent (National Center for Health Statistics 1990); in other words, cancer accounts for one out of nearly every four deaths. An action affecting a population of 20,000 people, with the estimated potential to induce one latent cancer fatality, should therefore be understood as adding one death from cancer (sometimes referred to as an excess cancer fatality) to a normally expected total of 4500 .

A note on risk factors: Dose-to-risk conversion factors can be, and are, expressed in several different ways in environmental documents. Each of the lists below gives four alternative ways of saying the same thing.

\begin{tabular}{|l|l|}
\hline \multicolumn{1}{|c|}{ Workers } & \multicolumn{1}{|c|}{ General Public } \\
\hline $4 \times 10^{-4}$ cancer deaths per person-rem* & $5 \times 10^{-4}$ cancer deaths per person-rem* \\
0.0004 cancer deaths per person-rem & 0.0005 cancer deaths per person-rem \\
1 cancer death per 2500 person-rem & 1 cancer death per 2000 person-rem \\
400 cancer deaths per 1 million person-rem & 500 cancer deaths per 1 million person-rem \\
\hline
\end{tabular}

*Remember that person-rem measures collective dose-i.e., the dose received by an entire population, not the dose received by an individual in that population.

It should also be noted that this calculation (dose equivalent times conversion factor) provides an approximation. The approximation is most valid when the result is 0.1 or less. For higher values, additional calculations are usually performed to obtain more precise predictions.

\section{Radiation Doses and Estimated Health Risks in NEPA Documents}

NEPA documents provide dose and health risk calculations for the affected general populations and the worker populations (divided, where applicable, into involved and noninvolved workers), for both routine (or incident-free) and accident conditions. In addition, when a project will continue for some time, estimates are given both for a single year and for the life of the project. Life-of-the 
project dose is calculated by multiplying the estimated annual dose equivalent by the expected number of years the project will continue.

For example, incident-free transportation activities for a proposed action are estimated to produce an annual collective dose equivalent of 0.4 person-rem among the worker population. To find out the dose and risk if the shipments in question were to continue for ten years, we multiply the collective dose by 10 ,

$$
0.4 \text { person-rem } \times 10 \text { years }=4 \text { person-rem, }
$$

and then calculate health risk in the usual way:

$$
4 \text { person-rem } \times 0.0004 \text { [occupational risk factor] }=0.0016 \text { (or, } 1.6 \times 10^{-3} \text { ). }
$$

In other words, the workers as a group have 1.6 chances in 1000 of experiencing an excess cancer fatality as a result of ten years of this exposure. With this method, dose equivalent and health effects can be calculated for any desired number of years.

Radiation health effects in NEPA documents can be expressed collectively (as the probability of a fatal cancer occurring within the group, or, if the answer is 1 or more, as the number of excess cancer fatalities expected to occur) and individually (as the estimated probability of the death of an individual). Individual risk (using rem rather than person-rem) is calculated in the same way as collective risk.

One individual calculation which is of particular interest in NEPA documents is the dose and risk to the maximally-exposed individual in a worker or general public population (i.e., the person in that population who would receive the maximum individual dose). For example, a recent EA calculated that the maximum individual dose to a member of the public from an accidental release due to a building collapse would be $8.4 \mathrm{rem}$. Multiplying 8.4 rem by the risk factor for the general public $(0.0005)$ yields a four-in- 1000 chance that the individual will die of a cancer induced by radiation from this accidental release:

$$
8.4 \text { rem } \times 0.0005 \text { [general public risk factor] }=0.0042 \text {. }
$$

It is standard procedure in NEPA documents to discuss health risk in terms of both reasonably foreseeable effects and conservative estimates--that is, estimates which intentionally overstate the risk. Conservative estimates are achieved by, for example, basing dose-to-risk calculations on the dose equivalent to the maximally-exposed individual, and, in the case of accident scenarios, estimating the effects of the bounding accident, the accident with the greatest potential consequences.

\section{A Final Note on Estimating Health Risk}

Tracing health effects to very low doses of radiation--the kind of doses usually at issue in NEPA documents--is extremely difficult because of such factors as the long latency period for cancer and the large number of potential causes (League of Women Voters 1993, p. 18). Dose-to-risk conversion factors attempt to compensate by statistical means for some of this uncertainty; however, it must be remembered that they are based on data for high rather than low doses. Studies dedicated to improving our ability to predict radiation health effects are constantly in progress, nationally and intemationally, and risk conversion factors are periodically revised to incorporate new experimental and epidemiological information (DOE 1993). 


\section{REFERENCES}

League of Women Voters Education Fund. 1993. The Nuclear Waste Primer. New York, New York.

Murray, Raymond L. 1985. Understanding Radioactive Waste, 2nd edition. Columbus, Ohio.

National Center for Health Statistics. 1990. Vital Statistics of the United States ("Deaths, by Age and Leading Cause").

National Council on Radiation Protection and Measurements. 1987. Ionizing Radiation Exposure of the Population of the United States. NCRP Report No. 93. Bethesda, Maryland.

National Council on Radiation Protection and Measurements. 1987. Recommendations on Limits for Exposure to Ionizing Radiation. NCRP Report No. 91. Bethesda, Maryland.

Nuclear Regulatory Commission. 1991. Preamble to Standards for Protection Against Radiation. 56 Federal Register 23363.

United States Department of Energy. 1990. Radiation Protection of the Public and the Environment. DOE Order 5400.5.

United States Department of Energy. 1994. Radiological Control Manual. DOE/EH-0256T, Revision 1.

United States Department of Energy. 1993. Recommendations for the Preparation of Environmental Assessments and Environmental Impact Statements. Office of NEPA Oversight. 